\title{
Maternal Dental Health Knowledge and Its Relation to the Dental Caries Experience of Their Children in Mamyzawa Camp of Refugees in Erbil, Iraq
}

\author{
Bushra Rashid Noaman ${ }^{1}$, Rebwar Fadil Khalid ${ }^{2}$, Lezan Dawood Fattah ${ }^{3}$
}

${ }^{1}$ Paedodontic Department, Tishk International University, Erbil, Iraq, ${ }^{2}$ Tishk International University, Erbil, Iraq, ${ }^{3}$ Tishk International University, Dentistry Faculty, Conservative Department, Erbil, Iraq

Correspondence: bushra.rashid@tiu.edu.iq Tel.: + 9647510207481

Received: 10 March 2019; Accepted: 27 November 2019

\begin{abstract}
Objectives. This study aimed to evaluate the mothers' dental health knowledge and its relation to their children's oral health behavior and practice in a camp of refugees. Method. This descriptive cross-sectional observational study was conducted in Mamyzawa refugee camp in Erbil City, Iraq, in November 2017. Seventy-nine preschoolers (43 aged 4 years and 36 aged 5 years) and their mothers (79) were chosen for this study. The study was accomplished in two days. The first day the mothers' oral health knowledge, children's behavior towards oral hygiene, eating behaviors of their children and their use of dental services were assessed by a questionnaire. The day after, examinations of the dental health status of the children were performed. SPSS statistics software was used to analyze the collected data. Results. Mothers' knowledge of oral health was low, and $63 \%$ of the children had dental caries. Five-year old children had more dental caries $(77.8 \%)$ than the four-year old $(51.20 \%)$. Frequency of sweet consumption, brushing assistance, and irregular use of dental services were the main factors that had relation to the high dental caries in those children. Conclusion. The mothers living in Mamyzawa refugee camp do not have enough knowledge of oral health,
\end{abstract}

which was led to high caries prevalence among their children, indicating that an intensive education program is required for the mothers and oral health care for their children.

Key Words: Dental Health Survey - Dental Caries - Oral Health Knowledge - Refugees - Oral Health Behaviors.

\section{Introduction}

Conflicts in Iraq have forced some people to migrate to the safe parts of the country such as Kurdistan. Since the June 2014 attack by ISIS in Mosul and different parts of the center of Iraq, thousands of people have migrated to the north of Iraq (Kurdistan region). This migration changed the lives of those people, including their home, economics, and health. The priority for the migrant people was survival, which led to forgetting other basic health requirements. From these requirements were the oral health of the adults and their children. Forgetting these requirements led to a decline in their health over time. Refugees are a vulnerable population and have fewer opportunities for access to dental care because they have no voice to ask for what they need. This can lead to increased risk for problems in oral and general health (1).

Health care providers need to understand the refugees' perspectives about their prob- 
lems to be able to find solutions. Community-Based Participatory Research (CBPR) was recommended to recognize the factors that affect the oral health status of children (1). Since mothers have a major role in preserving the oral health of their children, mothers should work in collaboration with the researchers to take constructive action, and not only for increasing the researchers' knowledge about those populations. Therefore, it is necessary to include the mothers in all research involving an oral health promotion program for children since they have an important potential in motivating their children for oral health $(2,3)$.

There is an indication that refugees and migrant people and their children experience significantly inferior oral health than the non-migrant population, and an understanding of the reasons for this is needed (4). It is obvious that low socio-economic status has a negative impact on oral health. Dental caries prevalence is higher among socially disadvantaged populations, including those living in rural areas, indigenous and culturally diverse families, and those living in poverty $(5,6)$. Refugees are economically and socially deprived. In addition to their poverty, refugees complain about obstacles which prevent them from obtaining dental care. A pilot study conducted in Canada with a group of refugees concluded that the parents mentioned obstacles to maintaining early childhood oral health (ECOH) including the mood of the child, sugar intake control, and economic reasons (7). U.S. Surgeon General's Report stated that the impact of poor oral health on Quality of Life can affect vital functions such as eating and speaking which may restrict daily activities in school and family relations (8).

Strategies to meet the requirements of essential general and dental health of children in the refugees' culture must include health education plans for the entire family, and implementation of healthier mouth care and appropriate use of dental services. Behavioral and lifestyle factors and oral health care are important factors in reducing the prevalence and severity of dental caries (9). In a study performed in a refugee camp it was found that a common daily practice among all the refugee children was high sweet consumption, with a strong association between caries and frequent sugary diet consumption (10). While other research suggested that parents' oral health knowledge may alter the oral health habits of their children (11).

Thus, this study aimed to evaluate the dental caries experience and dental care practices among preschool children living in Mamyzawa camp, Erbil, Iraq and to study its relationship with mother's oral health knowledge and oral health behavior.

\section{Materials and Method}

This descriptive cross-sectional observational study was conducted in the Mamyzawa refugee camp in Mamyzawa province, Erbil City, northern Iraq, in November 2017.

\section{Materials}

Disposable mirrors and probes, Professional PenLite (white halogen light, Welch Allyn, (USA) were used in this study. World Health Organization Oral Health Assessment Form for Children, 2013 (Annex 2) (12) was used for the recording the severity of dental caries. Questionnaire papers, according to Annex 8, WHO (12) was used to collect information about children behaviors and maternal knowledge.

\section{Method}

\section{Selection and Description of Participants}

There were 470 children living in the camp with their families. From these children all the preschool children were chosen, since 
these refugees have no kindergarten and live in the camp since 2014. The children in this age group are entirely reliant on their homes for health care and eating habits. There were eighty-nine children aged 4-5 years, and after applying the inclusion and exclusion criteria, the total number who met the inclusion criteria was 79 children aged 4 years $(\mathrm{N}=43)$ and 5 years $(\mathrm{N}=36)$. The mothers of these children were included in answering the questionnaire. Totally cooperative children who gave good time without any movement during the examination, free of any disease systemically and mentally, and whose parents agreed to participate with their children in this study were included. The children who didn't meet these criteria were excluded from the study.

\section{Standardization and Calibration}

Four examiners shared the work of conducting the survey. To ensure uniform interpretation, understanding and training, and the index used in the survey, an interval of seven days passed between preparation and calibration, so the examiners had time to assimilate their knowledge of the index and practice conducting the survey (13). Intra-examiner reproducibility was assessed to eliminate variations within each examiner. The Kappa test was used to evaluate intraexaminer reproducibility. Each examiner examined 10 children and after 30 minutes he re-examined the same children to check the reproducibility. Almost perfect agreement was obtained for each examiner. The kappa test scores for dental caries assessment provided nearly perfect intra-examiner reliability $(0.92,0.90,0.90,0.93)$.

\section{Oral Health Knowledge Questionnaire}

The mothers of the 79 children answered the questionnaire. To obtain reliable information about the health status of their chil- dren and risks to health, in the first step, the questionnaire was pretested for clarity with 10 mothers. The questionnaire was conducted by means of an interview between the researchers and the mothers, the day before the dental examination. The language of the interview was according to the mothers' native languages (Kurdish or Arabic). The questionnaire was intended to evaluate the mothers' oral health knowledge and their children's oral health behavior and practice. The mothers' oral health knowledge included reasons for brushing, the exact amount of toothpaste needed for a child, the importance of visiting a dentist, the reason for visiting a dentist (pain or no pain), and the significance of fluoride. The mothers' knowledge about tooth brushing included the age when the child's tooth brushing should begin, frequency of brushing and if the child should be assisted during brushing or not. Frequency of sweet consumption and the time of sweets intake were included in the questionnaire. The use of dental facilities was assessed by previous dental visits and the type of treatment the child received on that visit $(10,12)$.

\section{Dental Examinations}

The children were examined for dental caries using disposable mirrors and disposable probes. Infection control measures were undertaken by using masks and gloves by the examiners and disposable trays, and all of those were changed for each child. The place of the examination was in the hall of the school in the camp, in sequence without crowding. The research assistants taught the children how to brush and monitored them during brushing before the examination. The time was early in the morning, so the examiners were not fatigued. The duration of the examinations was 3 hours for each examiner, in order to gain reliable results, which included time for rest. The examina- 
tions were performed on an ordinary chair using artificial light. The World Health Organization Oral Health Assessment Form for children, 2013, was used (12). The examination involved registration of the dentition status, which included decayed, missing due to caries and filled teeth (dmft). Caries is documented as extant when a lesion present on a smooth surface or in pits and fissures has an obvious cavity, in addition, undermined enamel, or obviously detected with softened floor. A tooth which is restored but carious and a tooth with temporary filling were included as decayed. The retained root of a tooth destroyed by caries was also considered as decayed (12).

\section{Ethics Statement}

The research started after agreement of the camp authority. Then the researchers gained the consents of parents. The consent included the fact that their children would undergo a dental examination and their mothers would answer a questionnaire related to oral health knowledge, attitudes and practice. This research started after approval had been granted by the research committee of Tishk International University, Erbil, Iraq (Document No.IU.RC.FR.001E). The research adhered to the World Medical Association Declaration of Helsinki.

\section{Statistical Analysis}

Data gained from the questionnaires and dental examinations were evaluated by statistical analysis software (IBM SPSS Statistics 22). The qualitative and quantitative variables were summarized using descriptive tables. The dependent variable is the percentage of caries prevalence (and mean $\mathrm{dmft}$ ) of the individual child was used as a reference for descriptive statistics. The independent variables used in this study included age, gender, dental health knowledge, oral hygiene habits, sweet consumption and dental visits. They were evaluated for association with dmft using the Chi-square and ANOVA tests, the level of significance was set at $\mathrm{P}<0.05$.

\section{Results}

Seventy-nine preschool children were living in the camp (42 males and 37 females). The children aged 5-years-old were more affected by dental caries $(77.8 \%, \mathrm{dmft}=3.55 \pm 3.79)$ than the 4-year-olds, but the difference in $\mathrm{dmft}$ was not statistically significant $(\mathrm{P}=0.068)$. Both males and females were nearly equally affected $(64.4 \%, 62.2 \%$ respectively). In total, $63 \%$ of the children had dental caries (Table 1).

Table 2 shows the mothers' knowledge about oral health care in relation to the mean dmft. Eighty-six percent of the mothers answered that tooth brushing is for preventing dental caries, and their children's dmft was $2.72 \pm 3.55$. The questionnaire revealed that they believe the amount of toothpaste used for tooth brushing is mostly filling the toothbrush (51.9\%, $\mathrm{dmft}=3.01 \pm 3.77$ ) followed by half a brush $(30.4 \%, \mathrm{dmft}=1.33 \pm 2.24)$, while only 14 mothers knew that the amount of toothpaste should be pea size ( $\mathrm{dmft}=2.07 \pm 2.23)$, with a statistically significant difference. Only two of the mothers knew the role of fluoride $(\mathrm{dmft}=1.5 \pm 2.12)$, and 77 mothers did not know ( $\mathrm{dmft}=2.94 \pm 3.60$ ), with no significant difference. Only $26.6 \%$ of the mothers knew the importance of the dental visit by asking the mother when the child should visit the dentist.

The children's toothbrushing and dental caries experience are shown in Table 3. Ninety one percent of children started brushing after three years of age $(\mathrm{dmft}=2.75 \pm 3.57)$. There was significant difference between the children whose frequency of brushing was more than 2 times a day compared with 
Table 1. Descriptive Statistics: Caries Prevalence and Severity, by Age and Gender

\begin{tabular}{lllllll}
\hline Variables & & $\mathrm{N}$ & Children affected $(\mathrm{N})$ & Caries $(\%)$ & Mean dmft \pm SD & $\mathrm{P}^{*}$ \\
\hline \multirow{2}{*}{ Age } & 4 years & 43 & 22 & 51.2 & $2.37 \pm 3.33$ & 0.068 \\
\cline { 2 - 7 } & 5 years & 36 & 28 & 77.8 & $3.55 \pm 3.79$ & \\
\hline \multirow{2}{*}{ Gender } & Male & 42 & 27 & 64.3 & $2.80 \pm 3.16$ & 0.336 \\
\cline { 2 - 7 } & Female & 37 & 23 & 62.2 & $3.03 \pm 4.04$ & \\
\hline
\end{tabular}

*One-Way ANOVA test: Significant difference at $\mathrm{P}<0.05$.

Table 2. The Relationship between Mother's Oral Health Care Knowledge and Children's dmft Index

\begin{tabular}{|c|c|c|c|c|}
\hline Variables & & $\mathrm{N}(\%)$ & Mean dmft $\pm S D$ & $\mathrm{P}^{*}$ \\
\hline \multirow{2}{*}{ Reason for brushing } & Prevent caries & $68(86.1)$ & $2.72 \pm 3.55$ & \multirow{2}{*}{0.062} \\
\hline & More cleanliness & $11(13.9)$ & $4.09 \pm 3.67$ & \\
\hline \multirow{3}{*}{ Amount of toothpaste } & Full & $41(51.9)$ & $3.01 \pm 3.77$ & \multirow{3}{*}{0.001} \\
\hline & Half & $24(30.4)$ & $1.33 \pm 2.24$ & \\
\hline & Pea size & $14(17.7)$ & $2.07 \pm 2.23$ & \\
\hline \multirow{2}{*}{ Importance of dental visit } & Check-up & $21(26.6)$ & $1.71 \pm 2.23$ & \multirow{2}{*}{0.076} \\
\hline & For pain & $58(73.4)$ & $3.34 \pm 3.87$ & \\
\hline \multirow{2}{*}{ Fluoride role } & Prevent caries & $2(2.5)$ & $1.50 \pm 2.12$ & \multirow{2}{*}{0.992} \\
\hline & I don't know & 77 (97.5) & $2.94 \pm 3.60$ & \\
\hline
\end{tabular}

"One-Way ANOVA Test; Significant difference at $\mathrm{P}<0.05$.

Table 3. Children's Toothbrushing and Dental Caries Experience

\begin{tabular}{|c|c|c|c|c|}
\hline Variable & & $(\mathrm{N}=79 ; \%)^{*}$ & Mean dmft $\pm S D$ & $\mathrm{P}^{+}$ \\
\hline \multirow{2}{*}{ Age of starting brushing } & 2 years & $7(8.9)$ & $4.50 \pm 3.41$ & \multirow{2}{*}{0.061} \\
\hline & $\geq 3$ & $72(91.1)$ & $2.75 \pm 3.57$ & \\
\hline \multirow{3}{*}{ Frequency of brushing/day } & 0 & $2(2.56)$ & 1 & \multirow{3}{*}{$0.030^{\ddagger}$} \\
\hline & 1 & $49(62.0)$ & $5.38 \pm 5.51$ & \\
\hline & $\geq 2$ & $28(35.4)$ & $2.44 \pm 2.89$ & \\
\hline \multirow{2}{*}{ Brushing assistance } & No & $48(60.8)$ & $3.41 \pm 4.039$ & \multirow{2}{*}{-0.043} \\
\hline & Yes & $31(39.2)$ & $2.58 \pm 3.247$ & \\
\hline
\end{tabular}

"Distribution of children in the sample; ${ }^{+} \mathrm{Chi}$ square was used: Significant difference at $\mathrm{P}<0.05$; ${ }^{\ddagger}$ Relates to comparing those who brushed one/ day with those who brushed twice or more a day.

children who brushed their teeth 1 time a day $(\mathrm{P}=0.030)$. Sixty one percent of mothers did not assist their children in brushing while $39.2 \%$ do, and there was significant difference at $\mathrm{P}<0.05$ between the $\mathrm{dmft}$ index score for both children $(3.41 \pm 4.03$ and $2.58 \pm 3.24$ respectively).

Table 4 illustrates the children's snacking behavior and dental caries experience. Ac- cording to the mothers, who were asked about the frequency of sweet intake in a day and its recommended time, two of the children never consumed sweets $(\mathrm{dmft}=1.5 \pm 0.77), 48$ children consumed sweets 1-2 times daily $(\mathrm{dmft}=2.48 \pm 3.88)$ and twenty-nine $\geq 3$ times daily $(\mathrm{dmft}=4.28 \pm 2.99)$, with a statistically significant difference. 
Table 4. Children's Snacking Behavior and Dental Caries Experience

\begin{tabular}{|c|c|c|c|c|c|}
\hline Variables & & $\mathrm{N}$ & With caries (\%) & Mean dmft $\pm S D$ & $\mathrm{P}^{*}$ \\
\hline \multirow{3}{*}{ Frequency of snacks } & Never & 2 & 100 & $1.50 \pm 0.77$ & \multirow{3}{*}{$0.031^{+}$} \\
\hline & $1-2$ & 48 & 54.1 & $2.48 \pm 3.88$ & \\
\hline & $\geq 3$ & 29 & 79.0 & $4.28 \pm 2.99$ & \\
\hline \multirow{3}{*}{ Time of snacks } & After meal & 50 & 56.0 & $2.92 \pm 3.91$ & \multirow{3}{*}{$0.538^{\ddagger}$} \\
\hline & Between meals & 27 & 34.2 & $2.81 \pm 3.05$ & \\
\hline & Before bedtime & 2 & 100 & $4.00 \pm 1.41$ & \\
\hline
\end{tabular}

Chi square was used: Significant difference at $\mathrm{P}<0.05$; †Relates to comparing those who had $1-2$ and $\geq 3$ frequency of snacks; $\neq$ Refers to the comparison between the means of $\mathrm{dmft}$ for the three types of time of snacks.

Table 5. Children's Dental Visits and Dental Caries Experience

\begin{tabular}{lllllll}
\hline Variables & & $\mathrm{N}$ & $\%$ and No of children & With caries \% & Mean dmft & $\mathrm{P}^{*}$ \\
\hline \multirow{2}{*}{ Has the child visited a dentist? } & No & 33 & $42 / 79$ & 84.7 & $4.41 \pm 3.90$ \\
\cline { 2 - 7 } 0.006 \\
\cline { 2 - 7 } When was the last dental visit? & Yes & 46 & $58 / 79$ & 33.3 & $0.82 \pm 1.42$ \\
\cline { 2 - 7 } & $>6$ months & 32 & $70 / 46$ & 87.5 & $5.214 \pm 4.40$ \\
\hline \multirow{2}{*}{ Type of treatment } & $<6$ months & 14 & $30 / 46$ & 78.5 & $3.939 \pm 3.69$ \\
\cline { 2 - 6 } & Examination & 28 & $60 / 46$ & 76.9 & $5.33 \pm 4.13$ \\
\cline { 2 - 6 } & Extraction & 12 & $27 / 46$ & 100 & $4.58 \pm 3.058$ \\
\cline { 2 - 6 } & Filling & 6 & $13 / 46$ & 100 & $3.923 \pm 4.26$ \\
\hline
\end{tabular}

Chi square test: Significant difference at $\mathrm{P}<0.05$.

Table 5 shows the use of dental services. The mothers were asked if the child had already visited a dentist. Forty-six of the children had visited a dentist before, and $33.3 \%$ of those children had caries $(\mathrm{dmft}=$ $0.82 \pm 1.42$ ), while 33 of the children had not visited a dentist and $84.7 \%$ of them had caries ( $\mathrm{dmft}=4.41 \pm 3.90)$ with a statistically significant difference $(\mathrm{p}<0.05)$. The answers about the last visit to the dentist revealed that most of the children had visited a dentist more than 6 months earlier (32/46), and only fourteen children had visited a dentist less than six months earlier (78.5\% caries) with $\mathrm{dmft} 5.214 \pm 4.405$ and $3.939 \pm 3.690$ respectively, with a statistically significant difference at $\mathrm{p}<0.05$. The questions showed that 28 of the children had their teeth examined and $76.9 \%$ of them had caries $(\mathrm{dmft}=5.33 \pm 4.13), 12$ had teeth extracted $(\mathrm{dmft}=4.58 \pm 3.058)$ and only six had fillings $(\mathrm{dmft}=3.92 \pm 4.26)$ with a statistically significant difference at $\mathrm{p}<0.05$.

\section{Discussion}

The aim of this study was to understand maternal dental health knowledge and its relation to the prevalence of dental caries in their children in Mamyzawa camp. There was no information available about the oral health, dental care practices and opinions of parents in the Mamyzawa refugees camp in Erbil especially those refugees who were living in the camp nearly for four years.

Mothers of preschool children were chosen to evaluate their knowledge about oral health. The dental status of this group of children would give information about the mothers' ability to take care of their oral health. In addition, this age is of importance in relation to caries in the primary 
teeth (12). The results show that $63 \%$ of the children living in the camp had dental caries. Five-year-old children were affected by dental caries more than the 4-year-olds (but this was not statistically significant), which agrees with other studies $(9,10)$. This indicates the continuation of increasing dental problems with increasing age (14). This also indicates that, those children will probably have more oral problems in the future.

The mothers have poor knowledge about the reasons for tooth brushing and their children had a high level of dental caries, even with mothers who know that the reason is for more cleanliness. This result agrees with Dgheim (10) as the sample was from refugees' camp. In this case, it is obvious that there is a gap between maternal knowledge and oral hygiene practices in their children. The mothers need to be motivated to understand the consequence of this neglect which may result from their difficult life away from their home.

Most of the children in this camp were brushing their teeth using dental brush and toothpaste. The recommended amount of toothpaste needed was not known by most of the mothers. This indicates the necessity for an education program about the effect of large amounts of toothpaste, since the child may swallow it increasing the risk for dental fluorosis (15). In general, the mothers do not know that they should visit the dentist regularly for a check-up. This also agrees with other researchers' findings $(9,10)$. Only two of the 79 mothers knew the role of fluoride $(2.5 \%)$, making the education essential to increase the caregivers' knowledge in the camp.

More than $91 \%$ of the children started brushing after 3 years of age and the frequency of brushing was once daily in more than half the children. In addition, $60 \%$ of the mothers did not know that they should assist their children in brushing their teeth, which agrees with a Saudi Arabia study which showed the importance of assisting the child during brushing (16).

Children's snacking behavior revealed that they had poor dietary habits, which is likely to have a negative effect on their dental health. Most of the children consume snacks $\geq 3$ times daily and had $\mathrm{dmf}=4.28$, which agrees with other studies $(10,17)$. Other factors such as mother's caries and early cariogenic feeding habits may be the reason why some children with low sweet consumption still have dental caries (11).

In general, most of the families in this camp only seek dental services when the child is in pain. Forty-two percent of the children had not visited a dentist $(\mathrm{dmft}=$ $4.41 \pm 3.90)$ and their caries experience was statistically significantly greater than that of those children who had visited a dentist. The other possible reason for the higher caries is the irregular visits to the dentist. Moreover, the most frequent service provided was examinations only, where $76.9 \%$ of them had caries, this agrees with the research conducted in a Palestinian refugee camp in Lebanon (10).

Refugees are vulnerable populations who have less chance of access to dental care because they lack a voice to speak up about what they need, and this can lead to increased risk of problems in their general health as well as oral health (1). Refugees have low economic status (7). In research about refugees' life, it was suggested that when refugees socialize with the citizens of the country in which they live, they have better access to dental services (18). Therefore, living in a camp can affect the lifestyle of the refugees (19). Refugee parents require applicable and valuable oral health education that recognizes their particular social health beliefs (4). In Iraq, dental services are very cheap in government health centers and can be accessed by poor people, in contrast to industrialized countries, such as Canada (20). Private dental universities also 
provide dental services at affordable prices; however, transportation is expensive which can be considered as an obstacle against utilizing the dental services by those refugees who live in the rural area of Erbil City. The results of this study show that the refugees in the current study need motivation and education in oral health care. In addition, the researchers suggest that there is a need for representatives, experts, scholars, and other sponsors to work to improve the oral wellbeing of refugees (21). Primary care physicians can have an important role in improving new refugee oral health by educating them about individual oral hygiene practices, the benefit of fluoride, and necessity of using preventive oral health services. In addition, the supervision by those physicians can often enable recommendations of dental services for the start of oral health care (22). In a review about maternal and child oral health in the Middle East, the authors concluded that implementing theory-driven oral health promotion programs, authorizing healthcare staff with oral health promotion tools will permit for timely access to preventive oral health treatment among mothers and children (23).

\section{Limitations of the Study}

Limitations of the study including lack of generalizability to other situations, limited to the age group studied, no inter-examiner reliability in the collection of data and, due to the cross-sectional study design, one cannot infer cause and effect.

\section{Conclusions}

This survey revealed that the mothers living in Mamyzawa camp have little knowledge of oral health and how to care for the dental health of their children. The main factors associated with the high prevalence and severity of caries as measured by the number of decayed, missed and filled primary teeth $(\mathrm{dmf})$ are the frequency of brushing, frequency of sweet consumption, brushing assistance, and irregular dental service usage. The researchers in this study suggest that these refugees need intensive oral health care, which should include scheduled oral examinations, treatment, oral health education and monitoring to influence health plans and programs in this camp. In addition, the mothers require an educational program on oral and dental health.

\section{What Is Already Known on this Topic:}

Refugees are a vulnerable population, lacking a voice to express what they need. The refugees in the Mamyzawa camp have lived for four years in this camp and they need intensive health care.

\section{What this Study Adds:}

The oral health status of the children in the camp was assessed by this study, in addition to the oral health knowledge of their mothers. This study revealed that the dental health of the preschoolers in this camp is poor, and there is a low level of dental knowledge.

Acknowledgments: The researchers would like to acknowledge the research assistants; Saya Hadi Rauf, Jwan Aras, Jwana Majid and Zhakaw Amang for their help in collecting data during the study. We acknowledge Tishk International University for the financial support for this study. Thanks to THD-Italy for their help in recruiting and directing the refugees during the study.

Authors' Contributions: Conception and design: RFK and BRN; Acquisition, analysis and interpretation of data: BRN, RFK and LDF; Drafting the article: BRN and LDF; Revising it critically for important intellectual content: BRN and RFK; Approved final version of the manuscript: BRN, RFK and LDF.

Conflict of Interest: The authors declare that they have no conflict of interest.

\section{References}

1. Olshansky E. The use of Community-Based Participatory Research to understand and work with Vulnerable Population. In: de Chesnay M, AndersonB, editors. Caring for the Vulnerable. 4th edition. Burlington, MA: Jones and Bartlett Publishers, LLC; 2016. p. 269-75. 
2. Moallemi S, Virtanen Z, Ghofranipour JI, Murtomaa $\mathrm{H}$. Influence of mothers' oral health knowledge and attitudes on their children's dental. health. Eur Arch Paediatr Dent. 2008;9(2):79-83.

3. Sarnat H, Kagan A, Raviv A. The relation between mothers' attitude toward dentistry and the oral status of their children. The AAPD. 1984;6(3):12831.

4. Riggs E, Gibbs L, Kilpatrick N, Gussy M, van Gemert C, Ali S, et al. Breaking down the barriers: a qualitative study to understand child oral health in refugee and migrant communities in Australia. Ethn Health. 2014;20(3):37-41.

5. Oliveira LB, Sheiham A, Bonecker M. Exploring the association of dental caries with social factors and nutritional status in Brazilian preschool children. Eur J Oral Sci. 2008;116(1):37-43.

6. Kilpatrick N, Neumann A, Lucas N, Chapman J, Nicholson J. Oral Health Inequalities in a National Sample of Australian Children Aged 2-3 and 6-7 Years. Aust Dent J. 2012;57(1):38-44.

7. Prowse S, Schroth RJ, Wilson A, Edwards J, Sarson J, Levi, JA, et.al. Diversity Considerations for Promoting Early Childhood Oral Health: A Pilot Study. Int J Dent. 2014;175084.

8. Evans CA, Kleinman DV. The Surgeon General's report on America's oral health: opportunities for the dental profession. J Am Dent Assoc. 2000;131(12):1721-8.

9. Israel BA, Schulz AJ, Parker EA, Becker AB. Review of community-based research: Assessing partnership approaches to improve public health. Annu Rev. Public Health. 1998;(19):173-202.

10. Dgheim T, Badr S, Ragab H. Relationship between caries experience and mothers' dental care knowledge and attitude among Palestinian refugees in Lebanon. IAJD. 2016;6(3):119-25.

11. de Silva-Sanigorski A, Ashbolt R, Green J, Calache H, Keith B, Riggs E, et. al. Parental self-efficacy and oral health-related knowledge are associated with parent and child oral health behaviors and self-reported oral health status. Community Dent Oral Epidemiol. 2012;41(4):1-8.

12. World Health Organization. Oral Health Surveys. Basic Methods. Design of an oral health survey, index ages and age groups. 5th ed. Geneva: WHO; 2013. [cited Dec 2019]. Available from: https://apps.who.int/iris/bitstream/handle/10665/97035/9789241548649_eng.pdf;jsessio nid $=$ CFC23471D0113CC209735222FD9CA547?s equence $=1$.

13. Eklund SA, Moller IJ, LeClercq MH, World Health Organization, The Oral Health Programme. Calibration of examiners for oral epidemiologic surveys. Geneva: WHO; 1993.

14. Mahejabeen R, Sudha P, Kulkarni SS, Anegundi R. Dental caries prevalence among preschool children of Hubli: Dharwad city. J Indian Soc Pedod Prev Dent. 2006;1;24(1):19-22.

15. Kanduti D, Sterbenk P, Artnik, B. Fluoride: a review of use and effects on health. Mater SocioMedica. 2016;28(2):133-7.

16. Al-Malik M, Holt R, Bedi R. Prevalence and patterns of caries, rampant caries, and oral health in two- to five-year-old children in Saudi Arabia. J Dent Child. 2003;70(3):235-42.

17. Hashim R, Williams SM, Thomson WM. Diet and caries experience among preschool children in Ajman, United Arab Emirates. Eur J Oral Sci. 2009;117(6):734-40.

18. Maserejian N, Trachtenberg F, Hayes C, Tavares M. Oral Health Disparities in Children of Immigrants: Dental Caries Experience at Enrollment and during Follow-Up in the New England Children's Amalgam Trial. Am J Public Health. 2008;68(1):14-20.

19. Bhalla A, Lapeyre F. Social Exclusion: Towards an Analytical and Operational Framework. Dev Change. 1997;28(3):413-33.

20. Ghiabi E, Matthews DC, Brillant MS. The oral health status of recent immigrants and refugees in Nova Scotia, Canada. J Immigr Minor Health. 2014;16(1):95-101.

21. Keboa MT, Hiles N, Macdonald ME. The oral health of refugees and asylum seekers: a scoping review. Global Health. 2016;12(1):59.

22. Cote S, Geltman P, Nunn M, Lituri K, Henshaw M, Garcia RI. Dental caries of refugee children compared with US children. Pediatrics. 2004;114(6):e733-40.

23. Abuhaloob L, MacGillivray S, Mossey P, Freeman R. Maternal and child oral health interventions in Middle East and North Africa regions: a rapid review. International Dental Journal. 2019;69:409-18. 